\title{
Single-Stage Flexible Uretero-Renoscopic Lasertripsy Clearance of Staghorn Stone
}

\author{
Vincent Koo* \\ Department of Urology, Alexandra Hospital, Worcestershire Acute Hospitals NHS Trust, United Kingdom \\ *Corresponding Author: Vincent Koo, Department of Urology, Alexandra Hospital, Worcestershire \\ Acute Hospitals NHS Trust, Woodrow Drive, Redditch West MidlandsB98 7UB, United Kingdom. Email: \\ v.koo@nhs.net
}

\begin{abstract}
An 83 year old frail lady presented with recurrent urinary tract infections and visible haematuria, and CT urogram subsequently revealed a left complete staghorn stone in a normal kidney. Her past medical history includes hearing loss, age-related macular degeneration, glaucoma, asthma, mild scoliosis and hypertension. She declined to undergo percutaneous nephrolithotomy due to the potential risk of viscus perforation and instead, insisted to undergo multiple staged flexible uretero renoscopic lasertripsy procedures. She did not have prior ureteric stent insertion. Her staghorn stone was completely cleared at her primary procedure after 135 mins. She did not have any postoperative complications and was fit to be discharged home the next day with a stent in-situ. Her ureteric stent was removed after 4 weeks and she remained asymptomatic. Her 3 months postop CTKUB showed dust-free status. This report discusses the technique and challenges of primary one-stage staghorn clearance using flexible uretero renoscopic lasertripsy.
\end{abstract}

Keywords: Flexible ureterorenoscopy, Lasertripsy, Retrograde intrarenal surgery, Staghorn stone, stent Abbreviations: UTI - urinary tract infection, CTKUB - CT kidney, ureter and bladder, PCNL Percutaneous nephrolithotomy, FURS - Flexible uretero-renoscopy, GA - General anaesthesia, PUJ - Pelvic ureteric junction

\section{INTRODUCTION}

Flexible Uretero Renoscopic (FURS) Lasertripsy is a recognised treatment for kidney stone less than $2 \mathrm{~cm}$. With improvement in scope technology and techniques, and also patient choice, endourologist continue to perform the procedure on stones size larger than $2 \mathrm{~cm}$. When compared to PCNL, there is a shorter hospital stay with less complication rate(Bryniarski et al, 2012). FURS has been found to be a safe and effective alternative treatment option for renal stones $>2 \mathrm{~cm}$ (Takazawa et al,2012; Giusti et al, 2014, Zengin et al, 2015).Previous authors have cleared staghorn calculi with multiple staged procedure (Ciccone et al, 2012) or when combined with percutaneous nephrolithotomy (PCNL) (Kawahara et al, 2012; Taguchi et al, 2015).Furthermore, recent evidence suggests that the acceptable stone size and volume for FURS would be $30 \mathrm{~mm}$ or $27000 \mathrm{~mm}^{3}$ respectively (Park et al, 2017). The main challenges of FURS lasertripsy in the treatment of staghorn stone are the risk for post-operative sepsis and the significant stone/dust burden to clear. This case of complete staghorn stone clearance by primary single-stage FURS lasertripsy alone is presented, and the technique and challenges are discussed.

\section{CASE REPORT}

This 83 year old frail lady presented with recurrent Ecoli UTI and visible haematuria to our One-stop Haematuria clinic. Her past medical history includes hearing loss, agerelated macular degeneration, glaucoma, asthma, mild scoliosis and hypertension. Her body mass index was 28 . Her flexible cystoscopy was normal and CT urogram and the 3dimensional reconstructed image in Figure1 showed a complete left staghorn (measured an average of 900 Hounsfield unit) adjacent to a calcified abdominal aorta.

Her daughters came back to clinic with her to discuss her treatment options. She was counselled and recommended for PCNL but she did not wish to undergo PCNL. Her daughters were concern about her frailty and worried about the potential risks of viscus perforation, bleeding, sepsis and mortality. She eventually consented to undergo multiple staged FURS 
lasertripsy and was put on prophylactic Trimethoprim). She received 5 days of $625 \mathrm{mg}$ oral Coamoxiclav before and after surgery. She was given $240 \mathrm{mg}$ IV Gentamicin 24 hours prior general anaesthetic (GA) induction.

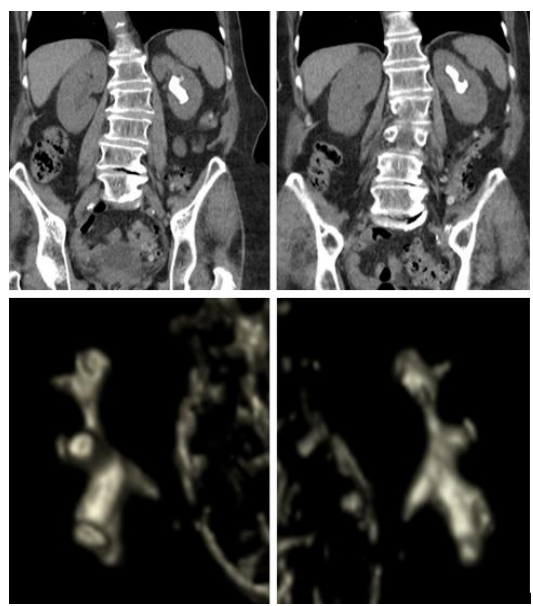

Figure1.CT scan and 3-Dimensional reconstruction images of staghorn stone

At GA induction, she received $160 \mathrm{mg}$ IV Gentamicin and 1.2g IV Coamoxiclav. She was put on lithotomy position with Bair Hugger ${ }^{\text {TM }}$ (3M, USA) normothermia system and Flowtrons ${ }^{\circledR} \quad$ (ArjoHunleight, Sweden) intermittent pneumatic compression device. 7F Karl-Storz®Semi-rigid Ureteroscope revealed the PUJ component of the staghorn into upper ureter. Boston Scientific Navigator ${ }^{\mathrm{TM}} 36 \mathrm{~cm}$ $11 / 13 \mathrm{~F}$ ureteric access sheath was inserted and Karl-Storz ${ }^{\circledR F l e x X C S}{ }^{\mathrm{TM}}$ flexible ureterorenoscopy was performed. Lasertripsy was done using 200um Boston Scientific Flexiva $^{\mathrm{TM}}$ Tractiplaser fibre, with short pulse $1.2 \mathrm{~J} \times 10 \mathrm{~Hz}$ from EMS Swiss LaserClast ${ }^{\circledR}$ (Nyon, Switzerland).

Figure 2 showed the serial screening fluoroscopic images, as the staghorn stone was lasered until completion. The staghorn stone was completely dusted after 2 hours $15 \mathrm{mins}$ and the procedure concluded with $24 \mathrm{~cm} 6 \mathrm{~F}$ ureteric stent. Postop KUB xray is shown in Figure 3. She was fit to be discharged home the next day.
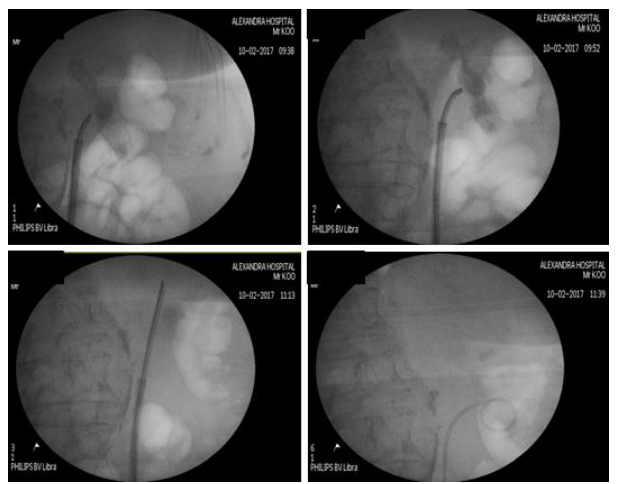

Figure2.Serial fluoroscopic images of staghorn stone clearance
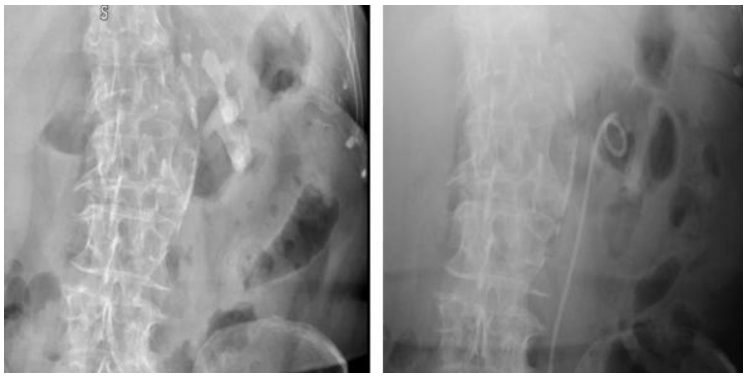

Figure3. Pre- and post-op KUB xray

Since her procedure and subsequent stent removal 4 weeks later, she has had no post operative complication and has been free of UTI or any symptoms. Her 3 months follow up CTKUB in Figure 4 did not show any residual stones or dust.
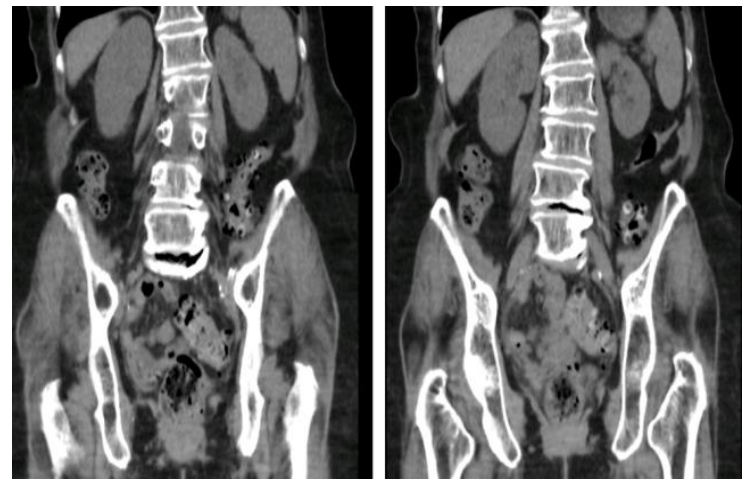

Figure4. Three months postop CTKUB images showing dust-free status

\section{DISCUSSION}

This report highlights complete staghorn stone clearance by primary FURS lasertripsy alone without prior-stent insertion. Concurrent use of a ureteric access sheath was essential in this case, allowing dust burden passage thus enabling clearer views, in order to progress efficiently with lasering of the staghorn. Lasering started with dusting of the PUJ "tail" of the staghorn to gain access to the body of the staghorn calculi. The ureteric sheath was then advanced into the renal pelvis to ensure low pressure within kidneys to minimise bacteraemia. Although passing the ureteric sheath beyond PUJ is not recommended, this would be the author's usual practice and no significant damage or stricture has been encountered in the author's experience.Bleeding usually ensued after the staghorn aspect directly in contact with the pelvi-calyceal lining was "freed" away by lasering. Pressured saline irrigation $(150 \mathrm{mmHg})$ was used to improve the endoscopic view.

The strategy of dusting continued to the upper body of the staghorn, creating a passage towards the upper pole. Akin to performing a transurethral resection of prostate (TURP), a 
"channel" was created to allow passage of dust and flow of saline irrigation fluid for adequate views. Hand-held irrigation pump was used to improve views and to carry out active "washout" of the dust particle downwards through to the ureteric access sheath.Upper pole stone dust tends to flow downwards the ureteric access sheath more easily due to a more direct path plus the aid of gravity, hence the rationale for lasering of the upper pole staghorn initially.

Once the upper pole was cleared, the "pelvic" portion of the staghorn was lasered. This was the more straight forward part of staghorn to clear. When lasering the lower pole portion, the patient was positioned "head down" to aid flow of dust to the upper pole (which provides a better view and passage of dust down to the ureteric sheath). The lower pole staghorn was very adherent to the renal pelvi-calyceal lining and was placed in a difficult angle to reach with the laser fibre. The ureteric access sheath was withdrawn distally to the upper ureter, to allow better scope deflection and access to stone. Occasional nudge (with the scope) of the remnant staghorn edges, in order to reposition the stone was useful to allow efficient lasering. After completion of staghorn dusting, a $6 \mathrm{~F}$ ureteric catheter connected to the saline irrigation to carry out washout of the dust. The procedure concluded with insertion of a ureteric stent and urethral catheter.

It is acknowledged that clearance of staghorn stone can also be safely done in staged settings, particularly in highly comorbid patients. This case describes a successful clearance of staghorn in a single setting, arguably very useful in anaesthetically challenging cases in the future.

\section{Conclusion}

In the context of staghorn calculi treatment, FURS lasertripsy can offer a viable and safe alternative treatment.

\section{REFERENCES}

[1] Bryniarski P, Paradysz A, Zyczkowski M, Kupilas A, Nowakowski K, Bogacki R. A randomized controlled studyto analyze the safety and efficacy of percutaneous nephrolithotripsy and retrograde intrarenal surgery in the management of renal stones more than $2 \mathrm{~cm}$ in diameter. J Endourol. 2012;26(1):52-7.

[2] Giusti G, Proietti S, Luciani LG, et al. Is retrograde intrarenal surgery for the treatment of renal stones with diameters exceeding $2 \mathrm{~cm}$ still a hazard? Can J Urol. 2014;21(2):7207-12.

[3] Takazawa R, Kitayama $\mathrm{S}$ and Tsujii $\mathrm{T}$. Successful outcome of flexible ureteroscopy with holmium laser lithotripsy for renal stones $2 \mathrm{~cm}$ or greater. International Journal of Urology.2012;19: 264-267.

[4] Zengin K, Tanik S, Karakoyunlu N, et al. Retrograde intrarenal surgery versus percutaneous lithotripsy to treat renal stones 2$3 \mathrm{~cm}$ in diameter. Biomed Res Int. 2015; vol. 2015: Article ID 914231.

[5] Ciccone J, McCabe J, Eyre R. Case Report: Successful Staged Ureteroscopic Treatment of a $5 \mathrm{~cm}$ Staghorn Renal Calculus. Case Reports in Urology. 2012; vol. 2012:Article ID 873069.

[6] Kawahara T, Ito H, Terao H, et al.Ureteroscopy assisted retrograde nephrostomy for complete staghorn renal calculi.Curr Urol. 2012;6(2):1025.

[7] Taguchi K, Hamamoto S, Okada A, et al. First case report of staghorn calculi successfully removed by mini-endoscopic combined intrarenal surgery in a 2-year-old boy. Int. J. Urol. 2015;22: 978-980.

[8] Park J, Oh S, Cho MC, et al. Acceptable Criterion of Stone Burden and the Significant Factors to Choose Retrograde Intrarenal Stone Surgery or Miniaturized Percutaneous Nephrolithotomy for the Treatment of Renal Stones >10 mm. J Endourol 2017;31(10):10121018.

Citation Vincent Koo, Single-Stage Flexible Uretero-Renoscopic Lasertripsy Clearance of Staghorn Stone. ARC Journal of Urology.2017; 2(3):12-14 doi: dx.doi.org/ 10.20431/2456-060X.0203003

Copyright: (C) 2017 Authors. This is an open-access article distributed under the terms of the Creative Commons Attribution License, which permits unrestricted use, distribution, and reproduction in any medium, provided the original author and source are credited. 